\title{
Kualitas Pemberian Informasi Obat pada Pelayanan Resep Berdasarkan Kepuasan Pasien BPJS Puskesmas Kecamatan Cilandak
}

\section{Quality of Providing Drug Information Services Based on Satisfaction of BPJS Patient in Prescription Services Puskesmas Kecamatan Cilandak}

\author{
Ekadipta*, Muhammad Sadikin, Muhammad Rizqi Yusuf \\ Department of Pharmacy, Faculty of Science and Tecnology, \\ Institut Sains dan Teknologi Al-Kamal, \\ JI. Raya Kedoya AI-Kamal No. 2 Kebon Jeruk, Jakarta Barat 11520, Indonesia \\ *Corresponding author email: ekadipta@gmail.com
}

Received 25-7-2019

Accepted 25-11-2019

Available online 30-12-2019

\begin{abstract}
ABSTRAK
Pelayanan kefarmasian di puskesmas berperan penting dalam pelaksanaan upaya kesehatan bagi masyarakat, yaitu dengan pelaksanaan pemberian informasi obat untuk mendukung penggunaan obat. Pemberian informasi obat harus jelas agar pasien puas. Kualitas pelayanan kesehatan yang baik apabila dilakukan dengan standar dan menimbulkan kepuasan bagi pasien. Tujuan penelitian ini adalah untuk mengetahui kualitas pemberian informasi obat pada pelayanan resep berdasarkan kepuasan pasien BPJS rawat jalan di Unit Pelayanan Obat, Puskesmas Kecamatan Cilandak periode Agustus 2018. Desain penelitian ini adalah metode deskriptif kuantitatif dengan menerapkan Permenkes nomor 74 tahun 2016 dan Permenpan nomor 14 tahun 2017. Dari hasil penelitian diperoleh data bahwa kualitas pemberian informasi obat secara keseluruhan mendapatkan nilai Indeks Kepuasan Masyarakat (IKM) sebesar 77,21 dengan mutu $B$ dan kualitas baik. Berdasarkan karakteristik responden yang menyatakan kualitas baik yaitu jenis kelamin perempuan, usia 19-49 tahun dan 50-59 tahun, pendidikan terakhir SMP ke atas. Kualitas kurang baik dinyatakan oleh jenis kelamin lakilaki dan pendidikan terakhir SD ke bawah. Berdasarkan perunsur dengan kualitas sangat baik diperoleh pada sediaan, dosis, cara pakai, dan indikasi. Kualitas baik diperoleh pada nama obat. Kualitas kurang baik diperoleh pada cara penyimpanan dan efek samping. Kualitas tidak baik diperoleh pada kontraindikasi, stabilitas, dan interaksi obat.
\end{abstract}

Kata kunci: BPJS, IKM, kepuasan pasien, pelayanan informasi obat, puskesmas. 


\begin{abstract}
Pharmacy services at the Community Health Centers, particularly drug information service, play an important role in the implementation of health efforts for the community. The provided drug information service must be clear for patient satisfaction. A good quality health service can be achieved by following the standards and hence resulted in satisfaction for patients. The purpose of this study was to determine the quality of drug information provided by the drug service unit of Cilandak Community Health Center based on the satisfaction of BPJS outpatients in August 2018. This study used a quantitative descriptive method by applying Permenkes number 74 of 2016 and Permenpan number 14 of 2017. The results of the study showed that the overall quality of drug information service received the Community Satisfaction Index value of 77.21, which represented $B$ for good quality. The characteristics of respondents who stated good quality were female, age 19-49 and 50-59 years old, junior high and higher education, while those stated not good one were male with elementary school and below education. The elements with very good quality were drug preparations, dosage, method of use, and indication; while that with good quality was the name of the drug. In addition, poor quality element was the storage method and side effects, with contraindications, stability, and drug interactions were named as the bad quality elements.
\end{abstract}

Key words: BPJS, drug information services, IKM, patient satisfaction, Puskesmas.

\section{Pendahuluan}

Peraturan Badan Penyelenggara Jaminan Sosial Kesehatan nomor 3 tahun 2017 menjelaskan bahwa BPJS Kesehatan adalah badan hukum yang dibentuk untuk menyelenggarakan program jaminan kesehatan. Upaya kesehatan adalah setiap kegiatan untuk memelihara dan meningkatkan kesehatan (Notoatmodjo, 2010).

$$
\text { Pelayanan kefarmasian di }
$$

puskesmas menurut Peraturan Menteri Kesehatan Republik Indonesia nomor 74 tahun 2016 tentang Standar Pelayanan Kefarmasian di Puskesmas merupakan satu kesatuan yang tidak terpisahkan dari pelaksanaan upaya kesehatan. Sesuai dengan perkembangan di bidang kefarmasian, telah terjadi pergeseran orientasi pelayanan kefarmasian, tidak saja sebagai pengelola obat, namun lebih luasnya mencakup pelaksanaan pemberian informasi untuk mendukung penggunaan obat (Kemenkes, 2010). Informasi yang tepat dan benar dalam penggunaan obat sangat penting dalam menunjang keberhasilan terapi (Kemenkes, 2011). Tidak tersampaikannya informasi secara baik, mutlak menjadi tanggung jawab apoteker atau petugas penyerah obat (Oscar dan Jauhar, 2016).

Laporan kinerja Direktorat Jenderal Pelayanan Kefarmasian tahun 2017 menjelaskan bahwa puskesmas yang melaksanakan pelayanan kefarmasian sesuai standar adalah puskesmas yang telah menerapkan pemberian informasi obat (PIO) dan terdokumentasi. Berdasarkan laporan 
tersebut, puskesmas yang telah melaksanakan pelayanan kefarmasian sesuai standar pada tahun 2016 adalah sebesar 45,39\% dengan target 45\%. Diharapkan pada tahun 2018 puskesmas yang melaksanakan pelayanan kefarmasian sesuai standar mencapai target 55\% (Kemenkes, 2017).

Terdapat sepuluh unsur PIO pada pelayanan resep yang tercantum dalam Permenkes nomor 74 tahun 2016. Namun tidak semua unsur informasi obat tersebut diberikan kepada pasien. Berdasarkan penelitian oleh Adityawati et al. (2016), unsur informasi obat yang tidak disampaikan di puskesmas adalah penyimpanan dan stabilitas obat. Serta dalam pemberian informasi obat harus jelas agar pasien puas. Kualitas pelayanan dinilai berdasarkan nilai persepsi dari kepuasan masyarakat menurut Peraturan Menteri Pemberdayagunaan Aparatur Sipil Negara dan Reformasi Birokrasi Republik Indonesia nomor 14 tahun 2017. Kualitas pelayanan kesehatan yang baik apabila dilakukan dengan standar dan menimbulkan kepuasan bagi pasien (Permatasari, 2015).

Puskesmas Kecamatan Cilandak merupakan salah satu fasilitas pelayanan kesehatan tingkat pertama yang menyelenggarakan upaya kesehatan bagi masyarakat. Survei yang telah dilakukan di Unit Pelayanan Obat Puskesmas Kecamatan Cilandak terhadap pemberian informasi obat pada pelayanan resep sudah terlaksana. Namun, belum mencakup seluruh unsur pemberian informasi obat yang tercantum pada Permenkes nomor 74 tahun 2016. Selain itu, masih ada pasien yang meminta penjelasan ulang mengenai informasi obatnya. Hal ini menunjukkan bahwa pasien belum puas terhadap pemberian informasi obat pada pelayanan resep. Oleh karena itu, perlu dilakukan penelitian yang bertujuan untuk mengetahui kualitas pemberian informasi obat pada pelayanan resep berdasarkan kepuasan pasien BPJS rawat jalan di Unit Pelayanan Obat, Puskesmas Kecamatan Cilandak periode Agustus 2018.

\section{Metode Penelitian}

Penelitian ini didesain dengan metode deskriptif kuantitatif. Penelitian deskriptif kuantitatif merupakan metode dengan memperoleh data berupa angka dari sampel populasi penelitian, dianalisis sesuai dengan metode statistik yang digunakan untuk diintrepretasikan (Riduwan, 2006).

Waktu pengambilan data pada hari Senin sampai dengan Jumat dari tanggal 1 Agustus 2018 hingga 31 Agustus 2018. Tempat pengambilan data adalah di Unit Pelayanan Obat, Puskesmas Kecamatan Cilandak, beralamat di Jalan Komplek BNI 46 nomor 57 RT 04/RW 05, Kelurahan Cilandak Barat, Kecamatan Cilandak, Jakarta Selatan.

Jumlah populasi berdasarkan Laporan Penerimaan dan Lembar Permintaan Obat (LPLPO), yaitu jumlah kunjungan pasien BPJS rawat jalan pada bulan April 2018 yang berjumlah 7.984. Maka jumlah unit sampel pasien dapat 
dihitung dengan menggunakan rumus Lwanga dan Lemeshow (Aprinansyah, 2017):

$\mathrm{n}=\frac{N x z \alpha^{2} x p x(1-p)}{d^{2} x(N-1)+Z \alpha^{2} x p x(1-p)}$

$\mathrm{n}=\frac{7.984 x 1,96^{2} \times 0,5 x(0,5)}{0,05^{2} x(7.983)+1,96^{2} \times 0,5 x(0,5)}$

$\mathrm{n}=367$

Keterangan:

$\mathrm{n}=$ jumlah sampel,

$\mathrm{N}=$ Jumlah populasi

$Z \alpha=$ Nilai baku distribusi normal pada derajat kepercayaan $95 \%$ adalah 1,96 .

$\mathrm{P}=$ Estimastor proporsi populasi sebesar $50 \%$.

$d=$ Toleransi kesalahan sebesar $5 \%$.

Hasil perhitungan tersebut sesuai dengan jumlah sampel untuk populasi sebesar 8.000 menurut
Permenpan nomor 14 tahun 2017 adalah sebanyak 367. Dengan kriteria inklusi:

1. Pasien BPJS rawat jalan.

2. Pasien dewasa (19 sampai 49 tahun) dan pasien pralansia (50 sampai 59 tahun) yang menebus obatnya sendiri.

3. Pasien anak dan remaja (18 tahun ke bawah), pasien lansia (60 tahun ke atas), dan pasien jiwa yang menebus obatnya diwakilkan orang dewasa atau pralansia.

Kualitas pemberian informasi obat berdasarkan kepuasan pasien BPJS rawat jalan dapat diketahui dengan menggunakan metode perhitungan yang mengacu kepada Permenpan nomor 14 tahun 2017.

Tabel 1. Nilai persepsi, konversi, dan kualitas kinerja

\begin{tabular}{ccc}
\hline Nilai Persepsi & Nilai Konversi & Kualitas Kinerja \\
\hline 1 & $25,00-64,99$ & Tidak baik \\
2 & $65,00-76,60$ & Kurang baik \\
3 & $76,61-88,30$ & Baik \\
4 & $88,31-100,00$ & Sangat baik \\
\hline
\end{tabular}

\section{Hasil dan Pembahasan}

Kualitas Pemberian Informasi Obat Perresponden

Kategori laki-laki menghasilkan nilai Indeks Kepuasan Masyarakat (IKM) sebesar 74,90 di antara nilai 64,99 dan 76,60 dengan kualitas kurang baik. Sedangkan pada kategori perempuan menghasilkan nilai IKM sebesar 78,07 di antara nilai 76,60 dan 88,30 dengan kualitas baik. Jenis kelamin merupakan salah satu faktor yang dapat mempengaruhi individu dalam menyikapi suatu produk jasa pelayanan (Kotler dan Keller, 2009). Mengetahui jenis kelamin, maka akan mempengaruhi pendapat atau penilaian seseorang mengenai sesuatu. Dalam hal ini mengenai penilaian kualitas pemberian informasi obat di Puskesmas Kecamatan 
Cilandak. Jenis kelamin laki-laki kurang peduli dibandingkan perempuan terhadap kesehatan, sehingga jenis kelamin memiliki pengaruh pada pandangan terhadap jasa yang diberikan (Gunarsa dan Gunarsa, 2008).

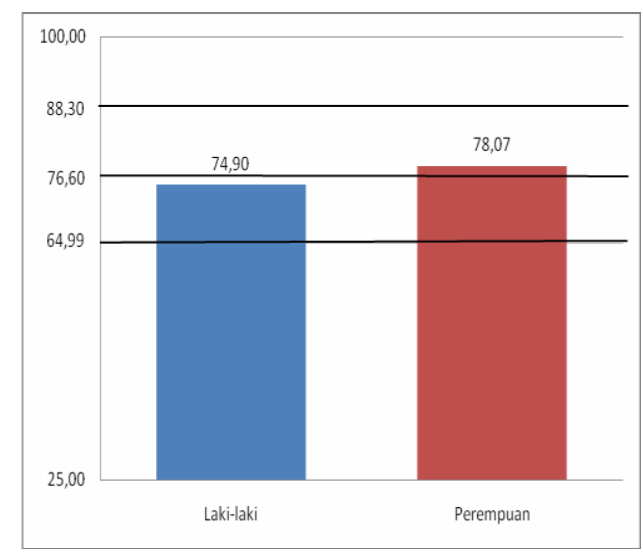

Gambar 1. Diagram indeks kepuasan masyarakat berdasarkan jenis kelamin.

Kategori usia yaitu dewasa 19-49 tahun dan pralanjut usia (pralansia) 5059 tahun. Pengelompokkan usia berdasarkan poli di Puskesmas Kecamatan Cilandak. Hasil IKM pada kedua kategori memperoleh nilai yang sama yaitu di antara 76,60 dan 88,30 dengan kualitas baik. Bertambahnya umur seseorang dapat berpengaruh pada kesehatannya, dimana terjadi kemunduran struktur dan fungsi organ, sehingga masyarakat yang berusia lebih tua cenderung lebih banyak memanfaatkan pelayanan kesehatan dibandingkan dengan usia dewasa (Gunarsa dan Gunarsa, 2008). Usia merupakan salah satu faktor dalam menentukan penilaian seseorang. Berdasarkan usia seseorang, dapat ditentukan penilaian konsumen, karena dengan pengetahuan, pandangan, dan pengalaman pada masa lalu akan mempengaruhi penilaian atau persepsi seseorang dalam mendapatkan pelayanan yang memuaskan terhadap sesuatu (Kotler dan Keller, 2019).

Kualitas pemberian informasi obat berdasarkan pendidikan terakhir dengan kategori yaitu SD ke bawah, SMP, SMA, D1-D3-D4, S1, dan S2 ke atas. Pendidikan terakhir dengan kategori SD ke bawah memperoleh IKM terkecil dengan nilai 74,86 di antara nilai 64,99 dan 76,60 dengan kualitas kurang baik. Sedangkan pada kategori SMP, SMA, D1D3-D4, S1, dan S2 ke atas memperoleh IKM di antara 76,60 dan 88,30 dengan kualitas baik. Salah satu faktor yang mempengaruhi persepsi adalah tingkat pendidikan. Tingkat pendidikan yang semakin tinggi akan berpengaruh terhadap pengetahuan, daya tangkap, 
informasi atau pilihan sehingga dengan pendidikan yang tinggi diharapkan akan memberikan penilaian yang obyektif (Arimbawa, 2014). Dengan demikian seseorang berpendidikan tinggi akan lebih mudah menerima informasi sehingga merespon kualitas pemberian informasi obat pada pelayanan resep dengan baik.

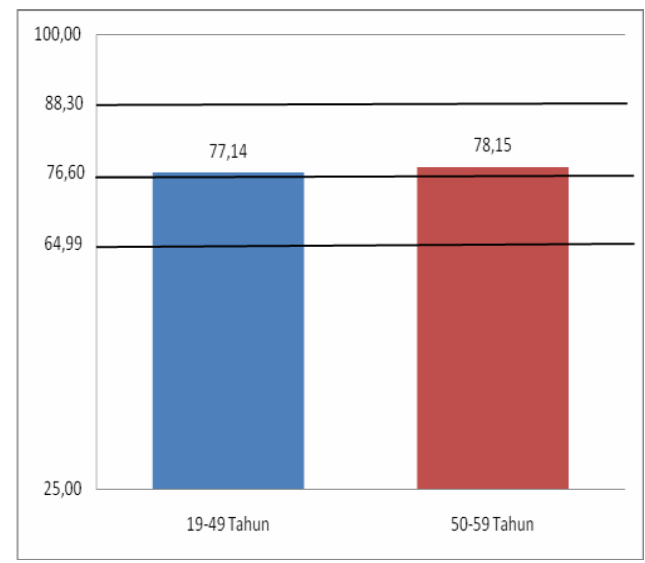

Gambar 2. Diagram indeks kepuasan masyarakat berdasarkan usia.

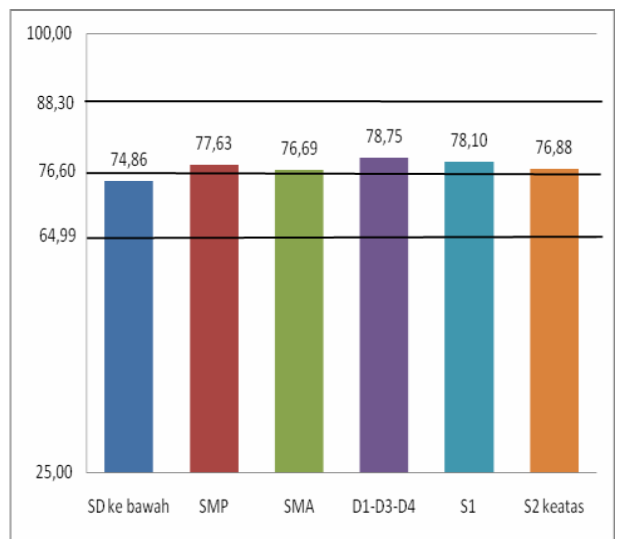

Gambar 3. Diagram indeks kepuasan masyarakat berdasarkan pendidikan terakhir.

Kualitas Pemberian Informasi Obat Perunsur

Unsur-unsur pemberian informasi obat ditentukan berdasarkan Permenkes nomor 74 tahun 2016.
Kategori pemberian informasi obat yang pertama adalah nama obat. Untuk kategori ini mendapatkan nilai IKM 88,15 dengan kualitas baik. Pemberian informasi obat tentang nama obat 
haruslah diberikan agar pasien dengan kualitas sangat baik. Semua mengetahui nama obat khususnya nama bentuk obat mempunyai karakteristik generik.

Pemberian informasi obat kategori kedua adalah sediaan obat. Nilai IKM yang diperoleh sebesar 93,26 dan tujuan tersendiri. Maka pemberian informasi obat tentang sediaan perlu diberikan agar tepat dalam penggunaan obat.

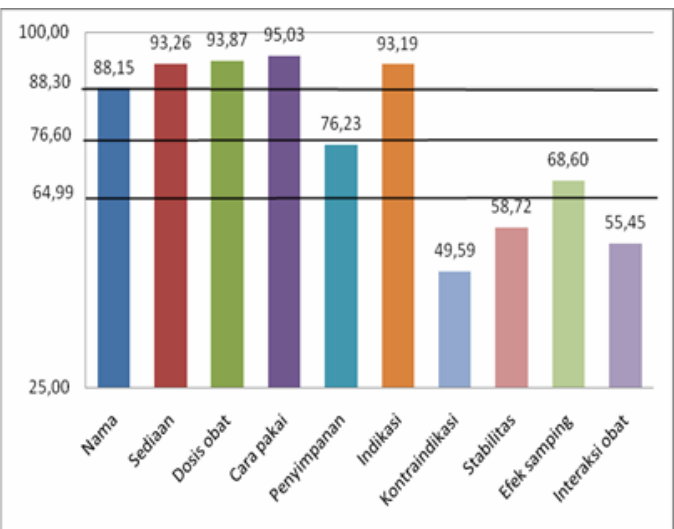

Gambar 4. Diagram indeks kepuasan masyarakat berdasarkan perunsur.

Dosis obat memperoleh nilai IKM 93,87 dengan kualitas sangat baik. Pemberian informasi obat di Puskesmas Kecamatan Cilandak tentang dosis obat meliputi aturan pakai dan jumlah gram zat aktif yang dikandung obat. Obat pada dasarnya merupakan bahan yang hanya dengan dosis tertentu dan dengan penggunaan yang tepat dapat dimanfaatkan untuk mendiagnosa, mencegah penyakit, menyembuhkan, atau memelihara kesehatan (Kemenkes, 2008). Sehingga pemberian informasi obat tentang dosis perlu diberikan kepada pasien agar obatnya bermanfaat.

Nilai IKM tertinggi yaitu 95,03 dengan kualitas sangat baik diperoleh pemberian informasi obat pada kategori cara pakai. Jadwal waktu dan rute penggunaan obat merupakan bagian dari cara pakai obat (Zeenot, 2013). Pemberian informasi obat tentang cara pakai terkait jadwal waktu penggunaan obat yang dinyatakan dalam berapa kali sehari atau setiap beberapa jam seperti 3 kali sehari setiap 8 jam (Widodo, 2004). Pada rute penggunaan obat dibedakan menjadi pemakaian dalam dan luar. Maka pemberian informasi obat tentang cara pakai perlu diberikan agar tepat penggunaannya, seperti obat wasir jangan ditelan (Kemenkes, 2008).

Cara penyimpanan mendapatkan IKM dengan nilai 76,23 dengan kualitas kurang baik. Berdasarkan pengamatan pemberian informasi obat tentang cara penyimpanan diberikan hanya untuk 
obat tertentu, jika tidak mendapatkan obat tertentu maka tidak diberikan informasi cara pemakaian obat, sehingga mendapatkan kualitas kurang baik. Obat tertentu seperti suppositoria disimpan di tempat sejuk karena dalam suhu kamar akan mencair. Obat disimpan sesuai aturan dengan tujuan obat terhindar dari kerusakan. Bila cara penyimpanan obat tidak memenuhi persyaratan cara menyimpan obat yang benar, maka akan terjadi perubahan sifat obat tersebut, sampai terjadi kerusakan obat (Kemenkes, 2008). Oleh sebab itu, pemberian informasi obat tentang cara penyimpanan perlu diberikan agar obat tidak rusak.

Kategori pemberian informasi obat selanjutnya adalah indikasi obat. Nilai IKM yang diperoleh pada kategori ini sebesar 93,19 dengan kualitas sangat baik. Indikasi obat merupakan informasi mengenai khasiat obat untuk suatu penyakit dan obat yang diberikan harus sesuai penyakit (Kemenkes, 2008). Sehingga pemberian informasi obat tentang indikasi perlu diberikan supaya pasien mengetahui manfaat obat untuk suatu penyakit.

Setelah kategori indikasi adalah kontraindikasi obat. Kategori ini memperoleh IKM dengan nilai terendah yaitu 49,59 dengan kualitas tidak baik. Menurut pengamatan, pemberian informasi obat tentang kontraindikasi diberikan jika pasien hamil dan atau menyusui. Sehingga pemberian informasi obat tentang kontraindikasi mendapatkan nilai yang tidak baik. Kejelasan tentang pemberian informasi obat terkait kontraindikasi bertujuan agar pasien tidak menggunakan obatnya jika memiliki kontraindikasi yang dimaksud (Trihono, 2005).

Kategori pemberian informasi obat yang berikutnya adalah stabilitas. Untuk kategori ini mendapat nilai 58,72 dengan kualitas tidak baik. Pemberian informasi obat tentang stabilitas terkait dengan tanggal kadaluarsa yang menunjukkan bahwa sampai dengan tanggal yang dimaksud, mutu dan kemurnian obat dijamin masih tetap memenuhi syarat, yang biasanya dinyatakan dalam bulan dan tahun (Kemenkes, 2006). Berdasarkan pengamatan, stabilitas obat diberikan untuk obat tertentu seperti puyer terkait lama waktu penyimpanan dan obat yang mendekati tanggal kadaluarsa atau kemasan obat yang dipotong. Jika tidak mendapatkan obat tersebut, maka tidak diberikan informasi obat tentang stabilitas, sehingga kualitasnya tidak baik. Oleh karena itu pemberian informasi obat tentang stabilitas perlu diberikan agar pasien menggunakan obat dengan mutu yang terjamin.

Efek samping obat merupakan bagian dalam pemberian informasi obat dengan nilai 68,60 dan kualitas kurang baik. Efek samping obat adalah efek yang tidak diinginkan untuk tujuan terapi (Siregar, 2004). Karena efeknya tidak diinginkan sehingga perlu berhatihati ketika memberikan informasi tentang efek samping obat agar pasien tidak takut untuk menggunakan obat. Pemberian informasi obat terkait efek samping di Puskesmas Kecamatan 
Cilandak seperti mengantuk pada obat klorfeniramin maleat (Granthina, 2016). Tujuan pemberian informasi obat ini agar pasien tidak menggunakan obat tersebut ketika akan berkendara. Sehingga pasien waspada terhadap efek samping.

Kategori interaksi obat mendapat nilai 55,45 dengan kualitas tidak baik. Obat dapat berinteraksi dengan makanan atau minuman, zat kimia atau dengan obat-obatan lain (Noviana dan Nurilawati, 2017). Pemberian informasi obat terkait interaksi berdasarkan pengamatan, seperti pemberian sediaan besi dengan kalsium laktat yang absorbsinya berkurang dengan pemberian kalsium.
Adapun amlodipin berinteraksi dengan simvastatin berpotensi meningkatkan miopati (Medscape, 2018). Pemberian informasi obat di Unit Pelayanan Obat Puskesmas Kecamatan Cilandak terhadap obat tersebut yaitu kalsium laktat digunakan pada pagi hari, sedangkan ferro sulfat pada malam hari. Penggunaan amlodipin dan simvastatin tidak secara berbarengan. Jika pasien tidak mendapatkan obat itu, maka tidak diberikan informasi interaksi obat, sehingga kualitas pemberian informasinya tidak baik. Pemberian informasi obat tentang interaksi obat bertujuan agar obat tidak digunakan secara berbarengan.

Tabel 2. Nilai indeks kepuasan masyarakat keseluruhan

\begin{tabular}{clc}
\hline No & Unsur Pemberian Informasi Obat & Indeks Kepuasan Masyarakat \\
\hline 1 & Nama & 88,15 \\
2 & Sediaan & 93,26 \\
3 & Dosis & 93,87 \\
4 & Cara pakai & 95,03 \\
5 & Cara penyimpanan & 76,23 \\
6 & Indikasi & 93,19 \\
7 & Kontraindikasi & 49,59 \\
8 & Stabilitas & 58,72 \\
9 & Efek samping & 68,60 \\
10 & Interaksi obat & 55,45 \\
Jumlah & 772,07 \\
Nilai Indeks Kepuasan Masyarakat & 77,21 \\
Mutu pelayanan & B \\
Kualitas kinerja & Baik \\
\hline
\end{tabular}

Kualitas Pemberian Informasi Obat Keseluruhan

$$
\text { Kualitas pemberian informasi }
$$

obat di Unit Pelayanan Obat, Puskesmas
Kecamatan Cilandak secara keseleruhan mendapatkan nilai IKM sebesar 77,21 dengan kualitas kinerja baik. Maka penerapan Permenkes no. 74 tahun 
2016 tentang standar pelayanan kefarmasian pada kategori pemberian informasi obat terlaksana dengan kualitas baik. Cara pemberian informasi obat kepada pasien harus mudah dimengerti, singkat tetapi jelas (Kemenkes, 2008). Informasi yang tepat dan benar dalam penggunaan obat sangat penting dalam menunjang keberhasilan terapi (Kemenkes, 2011). Pemberian informasi obat bermaksud agar pasien mengetahui tujuan dan mematuhi aturan pengobatan (Oscar dan Jauhar, 2016).

\section{Simpulan}

Penerapan Permenkes nomor 74 tahun 2016 tentang standar pelayanan kefarmasian di puskesmas pada Unit Pelayanan Obat, Puskesmas Kecamatan Cilandak terkait pemberian informasi obat sudah terlaksana dengan nilai IKM 77,21 dan kualitas baik. Kualitas baik dinyatakan oleh jenis kelamin perempuan, usia 19-49, 50-59 tahun, pendidikan terakhir SMP, SMA, D1-D3-D4, S1, dan S2 ke atas, sedangkan kualitas kurang baik dinyatakan oleh jenis kelamin laki-laki dan pendidikan terakhir SD ke bawah. Kualitas sangat baik diperoleh pada sediaan, dosis, cara pakai, dan indikasi. Kualitas baik diperoleh pada nama obat. Kualitas kurang baik diperoleh pada penyimpanan dan efek samping. Serta kualitas tidak baik diperoleh pada kontraindikasi, stabilitas, dan interaksi obat.

\section{Saran}

Saran yang diberikan bagi Puskesmas Kecamatan Cilandak, pada kualitas pemberian informasi obat berdasarkan perunsur yang memperoleh nilai sangat baik dan baik, perlu dipertahankan, sedangkan kualitas yang kurang baik dan tidak baik, perlu ditingkatkan. Untuk selanjutnya, teknologi seperti pesan SMS dan WhatsApp untuk memberikan informasi obat sebagai reminder bagi pasien perlu dimanfaatkan. Penelitian ini perlu dikembangkan menjadi hubungan antara kualitas pemberian informasi obat dan kepuasan pasien.

\section{Daftar Pustaka}

Adityawati, R., Latifah, E., Hapsari, W.S. 2016. Evaluasi pelayanan informasi obat pada pasien rawat jalan di Instalasi Farmasi Puskesmas Kecamatan Grabag. Jurnal Farmasi Sains dan Praktis, 1(2):6-10.

Aprinansyah, A. 2017. Kajian pelayanan informasi obat di apotek wilayah Kota Tanggerang. Skripsi. Program Studi Farmasi, Fakultas Kedokteran dan Ilmu Kesehatan, UIN Syarif Hidayatullah Jakarta.

Arimbawa, E., Suarjana, Wijaya, G. 2014. Hubungan pelayanan kefarmasian dengan kepuasan konsumen menggunakan jasa apotik di Kota Denpasar. Public Health and Preventive Medicine Archive, 2(2):198-203.

Direktorat Jenderal Bina Kefarmasian dan Alat Kesehatan. 2017. http://www.pio.binfar.depkes.g 
o.id. Data diakses pada 1 Oktober 2018.

Gunarsa, S.D. dan Gunarsa, Y.S.D. 2008. Psikologi Praktis: Anak, Remaja dan Keluarga. Jakarta: Gunung Mulia.

Granthina. 2016. Praktikum Spesialit dan Terminologi Kesehatan. Jakarta: Badan Pengembangan dan Pemberdayaan Sumber Daya Manusia Kesehatan.

Kementerian Kesehatan Republik Indonesia. 2006. Pedoman Penggunaan Obat Bebas dan Bebas Terbatas. Jakarta: Direktorat Jenderal Bina Farmasi dan Alat Kesehatan.

Kementerian Kesehatan Republik Indonesia. 2008. Materi Pelatihan dan Peningkatan Pengetahuan dan Keterampilan Memilih Obat bagi Tenaga Kesehatan. Jakarta: Direktorat Jenderal Bina Kefarmasian dan Alat Kesehatan.

Kementerian Kesehatan Republik Indonesia. 2010. Materi Pelatihan Manajemen Kefarmasian di Puskesmas. Jakarta: Direktorat Jenderal Bina Kefarmasian dan Alat Kesehatan.

\section{Kementerian Kesehatan Republik Indonesia. 2011. Modul Penggunaan Obat Rasional. Jakarta: Direktorat Jenderal Bina Pelayanan Kefarmasian.}

Kementerian Kesehatan Republik Indonesia. 2017. Laporan Akuntabilitas Kinerja 2016.
Jakarta: Direktorat Jenderal Bina Pelayanan Kefarmasian.

Kotler, P. dan Keller, K.L. 2009. Manajemen Pemasaran. Edisi 13. Jilid 1. Jakarta: Penerbit Erlangga.

Medscape.

https://reference.medscape.co $\mathrm{m} /$ drug-interactionchecker. Data diakses pada 1 Oktober 2018.

Notoatmodjo, S. 2010. Promosi Kesehatan Teori dan Aplikasi. Edisi Revisi 2010. Jakarta: Rineka Cipta.

Noviana, N. dan Nurilawati, V. 2017 Bahan Ajar Keperawatan Gigi Farmakologi. Jakarta: Pusat Pendidikan Sumber Daya Manusia Kesehatan.

Oscar, L. dan Jauhar, M. 2016. DasarDasar Manajemen Farmasi. Jakarta: Prestasi Pustaka.

Permatasari, D.W. 2015. Hubungan antara pemberian informasi obat dan lama pelayanan farmasi resep jadi dengan kepuasan pasien umum rawat jalan di Instalasi Farmasi RSUD Jendral Ahmad Yani. Skripsi. Fakultas Kedokteran, Universitas Negeri Lampung.

Riduwan. 2006. Metode dan Teknik Penyusunan Tesis. Bandung: Alfabeta.

Siregar, C. 2004. Farmasi Klinik. Jakarta: Buku Kedokteran EGC. 
PHARMACY: Jurnal Farmasi Indonesia

p-ISSN 1693-3591

(Pharmaceutical Journal of Indonesia)

e-ISSN 2579-910X

Vol.16 No. 02 Desember 2019:244-255

Trihono. 2005. Manajemen Puskesmas Berbasis Paradigma Sehat. Cetakan 1. Jakarta: Sagung Seto.

Obat. Yogyakarta: Kreasi Wacana.

Zeenot, S. 2013. Pengelolaan dan Penggunaan Obat Wajib

Widodo, R. 2004. Panduan Keluarga Apotek. Yogyakarta: D- Mediko. Memilih dan Menggunakan 